\title{
The young and the restless
}

Madrid. Hundreds of Spanish postdoctoral fellows, sent abroad for scientific training as Spain's economy took off in the 1980s, now find themselves stranded as the country's finances have faltered and the jobs to which they were expecting to return have failed to materialize. A new initiative by the cashstrapped government to provide short-term contracts for returning researchers has been decried as too little, too late, especially as the number of permanent positions is shrinking.

In 1984, post-Franco Spain began a concerted attempt to raise the low level of its research base, leading to the formulation in 1986 of the national research and development plan, which laid out a framework for research and development along European lines. As part of the plan, young scientists were sent abroad for pre- and postdoctoral training with an expectation of secure employment on their return to Spain. But the high hopes crashed along with the economy, and most of the new-minted researchers found themselves with little hope of a permanent job. Some short-term contracts, with poor employment conditions, were available, but from 1985 only 200 such contracts a year were offered - not enough to go round.

Moreover, Spain started and is continuing a campaign to train more $\mathrm{PhDs}$ at home: in 1991, more than 10,000 graduate fellowships were provided. According to José Mato, president of Spain's Council for Scientific Research (CSIC), the idea was to secure Spain's future by substantially increasing the research population. "Although it sounds obvious", he says, "to develop science in Spain, firstly we had to have scientists, and secondly we had to create for them places to work."

The second part of the plan has not been as successful as the first. Angel Pestaña, a molecular biologist at the CSIC Institute of Biomedical Research in Madrid, says that after a brief rise in the number of permanent positions for young scientific investigators in the early $1980 \mathrm{~s}$, the ratio of short-term to permanent contracts for young scientists has risen dramatically. The ratio in 1991 was about $4: 1$, but in Pestaña's discipline it is now about $10: 1$.

Roberto Fernandez de Caleya, director general of the Ministry of Education and Science, says that the government pays travel expenses for the Spanish researchers to come home, but cannot afford to give them permanent jobs. He estimates that about twothirds find temporary employment in research institutes and universities, but exact statistics are hard to come by because the government does not keep track of where the returning researchers end up.

Young scientists who have gone abroad are at a disadvantage because they must compete for jobs from a distance and against an increasing number of homegrown researchers. Permanent university jobs are advertised only in a closed circulation university magazine. Many returning scientists therefore take up, as an interim measure, special contracts which originally covered wages only and gave none of the usual employment rights, such as pension benefit or social security. Researchers on these contracts work on established projects and have no chance to develop their own research interests.

In response to the general dissatisfaction with this system, the government has established this year a new system of three-year contracts with full employment benefits. And there are more of them - 300 for 1992 and the same for next year. Most researchers, however, find this an insufficient improvement, particularly because it does not address the more basic problem of a shrinking availability of permanent research jobs in both the universities and industry.
The government is sensitive to the problem, but with its restricted budget it has no easy solution. In addition to tinkering with its short-term contract options, it is now looking to outside sources to help it out. Scientists are being encouraged to apply for funding from the European Community, and Spanish industry is being encouraged to share the burden (see below).

Not everyone is sympathetic to the plight of researchers. Iñigo Aguirre de Cárcer, subdirector at the Ministry of Education and Science, says that researchers make life harder for themselves because they are generally unwilling to consider positions outside the main centres in Madrid and Barcelona. Spain has a policy of devolving research and some openings are appearing in the provinces. But the virtual absence of scientific support in the provinces, compared to Madrid, which hosts at least half of all Spain's scientific activity, is unattractive for the ambitious.

Alison Abbott

\section{Running out of steam ...}

Munich. Since the restoration of democracy in the late 1970 s, Spanish research has grown much faster than in other Western economies. In the past ten years, Spain has more than doubled the percentage of gross national product (GNP) it allocates to research. But now the government says that the rate of growth cannot be sustained, and science is likely to stagnate at a level that remains one of the lowest in Europe.

In 1983 , Spain put only 0.48 per cent of GNP into research, much less than the 2 per cent average among Europe's richer nations. Since then, the government has raised research budgets generously - an average annual increase of more than 15 per cent and by last year research spending was up to 0.9 per cent of GNP. But economic collapse

\section{Research and development outlays in Spain}

Figures in thousand millions*

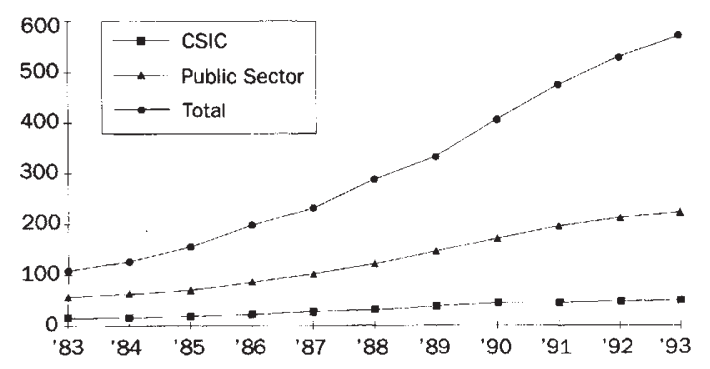

* 1991-1993 figures estimated

Source: 1983-90: OECD, INE. 1991-93: Nat. Plan, SDIC has forced the government to think again about the speed of modernization. In 1992 the science budget grew at a rate barely above inflation, and something similar is expected for 1993 .

The poor economy has necessitated hard thinking about spending priorities, but has Spain also lost the political will to bring its research base into line with the European Communities (EC)? 'Not so', says Elias Fereres, secretary of state for universities and research. Some decisions demonstrate the government's continuing commitment to research, he says; for example, education and science will be the only ministry exempt from the freeze on civil service appointments announced for 1993.

Fereres also stresses the positive achievements of Spanish research before the brakes were put on growth. Scientific productivity, as measured by the US Institute for Scientific Information, has doubled along with investment. Spain contributed 1.7 per cent of the world's scientific output in 1991, compared with 0.8 per cent in 1984 . The quality of papers has also increased, as judged by the usual parameters of impact factors and publication in Englishlanguage, refereed journals. Measured per researcher, Spanish output is on a par with the richest countries. And the introduction of the national plan in 1986, which for the first time forced a logical 
structure on its research plans, ensured that Spain established itself in important competitive areas such as biotechnology, engineering and microelectronics.

The increase in Spain's scientific stature has been largely led by the CSIC and its 96 research institutes, 42 of which are in Madrid. But CSIC is now also suffering a budget squeeze, with only a six per cent increase, close to the inflation rate, for 1993. Between 1983 and 1990, the average budget growth was around 17 per cent. There are no strong indications that the universities or industry will pick up the slack. According to Francisco Mora, a university professor in Madrid, "the scientific infrastructure in the universities is far behind that of CSIC". And Fereres admits that despite his government's encouragement, "Spain traditionally imports technology and industry lacks the commitment to do research." In 1988, the government introduced a scheme to pay for one-year contracts for young scientists to work in an industrial environment, and many research-linked tax incentives are now available. But the hope that this would stimulate the fledgling research and development culture in Spanish companies has not yet been fulfilled.

Another source of new money for Spanish science is the EC, and about 1,350 Spanish groups now participate in 955 different EC projects. But they are leaders in only 4 per cent of those projects, which is a measure of how far Spain is away from what Luis Oro, secretary general of the national plan, calls "the ultimate goal of reducing the gap separating Spain from the most advanced industrial countries." Oscar G. Segurado

\section{Physics centre threatened}

Washington. Fusion research at the Princeton Plasma Physics Laboratory (PPPL), one of the principal US fusion research centres, would be shut down for as long as nine years under a recent plan submitted to the US Department of Energy (DOE). The Fusion Energy Advisory Committee, which was asked by DOE to rank US fusion projects, recommended closure of the Princeton Beta Experiment-Modification (PBX-M) in 1994, on the grounds that the $\$ 10$ million annual cost would be better spent on the International Thermonuclear Experimental Reactor, to which the United States is a subscriber, and on PPPL's new project, the Tokamak Physics Experiment. The TFTR (Tokamak Fusion Test Reactor) at Princeton is scheduled to be shut down in 1994, and the Tokamak Physics Experiment is not due for completion until 2003. Closure of PBX-M will displace 25 scientists, unless the budget for fusion energy research rises by 5 per cent for the next several years, which seems unlikely in the light of this year's increase of only 0.8 per cent. Traci Watson

\section{Proposal opens debate over US data on animals}

Washington. A proposal that the US government should collect more data on research animals has renewed debate about the flaws in the existing system. Although many researchers believe that additional information is unnecessary and could be used by activists campaigning to eliminate animals from the laboratory, most agree that changes are needed in what is now collected.

At present, institutions must submit an annual report to the US Department of Agriculture (USDA) on animals used for

\section{Animals in the laboratory}

There were 1.8 million animals used in US experiments in 1991, excluding rats, mice and birds.

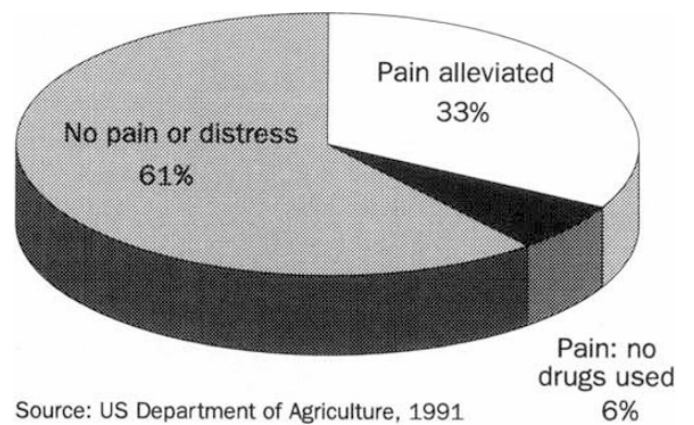

Proposed categories of pain and suffering

Category 1: Procedures involving the use of microorganisms, plants, invertebrates, vertebrate embryos, in vitro cultures, or no living organisms at all. Category Il: Procedures using vertebrates species that should produce little or no pain or discomfort.

Category III: Procedures that should produce minor or short-term pain or distress in vertebrate animals.

Category IV: Procedures involving significant (moderate to severe) but unavoidable pain or distress to vertebrate animals.

Category V: Procedures involving severe pain near, at, or above the pain tolerance or unanesthetized, conscious animals.

research, testing or education. Scientists have long complained that the rules for the annual report are vague and unreasonable, especially the requirement that all animals be placed into one of three categories that measure pain and distress: those experiencing no pain, those subjected to painful procedures and treated with alleviating drugs and those that undergo painful procedures without any alleviating drugs.

Reporting varies widely between institutions and among investigators. Even a simple injection may or may not be reported as painful, says Franklin Loew, dean of the school of veterinary medicine at Tufts University in North Grafton, Massachusetts.

Researchers and animal advocates agree that the present statistics are probably misleading. For example, USDA says that only
6 per cent of research animals are subject to painful procedures undrugged; many researchers think the figure is too high, and advocates contend that it is too low.

The Humane Society of the United States has submitted a proposal to USDA for a pain that provides "a better profile of what laboratory animals experience". Their scale has five categories, based on the degree of ure). Pain scales more extensive than USDA's are already used in some European countries and at least a dozen large US research institutions. In 1987, USDA proposed a detailed pain scale for use by the committees that oversee animal care at each institution, but it was withdrawn after researchers complained that it was vague and too subjective. Many are also concerned that such information would be used by animal advocates to turn public sentiment against the scientific community.

It is unlikely that USDA will support the Humane Society's request, but there is room for improvement. Many researchers believe that a thorough explanation of the reporting requirements would yield more accurate information, and they would like to work with the agency on such changes. "USDA has never come to the community asking for help", says one researcher. "Doing so would show that they're serious." Scientists believe they have an ally in Dale Schwindaman, the new director of the USDA department that collects the annual reports. They are encouraged by his agreement to rescind changes in a rule that would have made the statistics less accurate and by his appearance earlier this month at the annual meeting of the American Association of Laboratory Animal Science.

But substantive changes will demand more than just good will. The USDA department that oversees animal research is understaffed and overworked; compiling more information and explaining the current system may be asking too much. Both animal activists and scientists agree that a necessary first step would be a larger USDA budget.

Traci Watson 